\title{
Produção teológica em diálogo com a história: perspectivas teológicas e pastorais para uma práxis cristã no pós-pandemia da COVID-19
}

\author{
Theological production in dialogue with history: \\ theological and pastoral perspectives for a Christian \\ praxis in the post-COVID-19 pandemic
}

Welder Lancieri Marchini

\section{Resumo}

A produção teológica tem como uma de suas funções o ônus de oferecer diretrizes à comunidade eclesial de modo que esta possa estabelecer-se no mundo. O teólogo é aquele que, inserido no contexto histórico, busca respostas. Os tempos de pandemia impactaram a sociedade atual e, por consequência, a comunidade cristã. Tanto as práticas eclesiais quanto as dinâmicas sociais foram impactadas. Qual a função do pensamento teológico diante de situações como a da pandemia do coronavírus? A partir da concepção de uma Teologia histórica de Johann Baptista Metz, que entende a Teologia em seu aspecto hominizador - ou seja, que assume a condição humana - este artigo estabelece um diálogo entre a produção teológica e a pandemia. A Teologia assume seu aspecto práxico tornando-se capaz de, a partir do diálogo com a realidade histórica, construir horizontes. Os conceitos da obra de Metz não serão aqui aplicados à pandemia. Mas é possível entender a pandemia como um momento crucial para uma produção teológica que se situa na história.

Palavras-chave: Coronavírus. Johann Baptist Metz. Práxis cristã. 


\begin{abstract}
Theological production has as one of its functions the burden of offering guidelines to the ecclesial community so that it can establish itself in the world. The theologian is one who, inserted in the historical context, seeks answers. The pandemic times impacted today's society and, consequently, the Christian community. Both ecclesial practices and social dynamics were impacted. What is the role of theological thinking in the face of situations such as the coronavirus pandemic? Based on the conception of a historical theology by Johann Baptista Metz, who understands theology in its hominizing aspect - that is, it assumes the human condition - this article establishes a dialogue between theological production and the pandemic. Theology assumes its practical aspect, becoming capable of building horizons based on the dialogue with historical reality. The concepts of Metz's work will not be applied here to the pandemic. But it is possible to understand the pandemic as a crucial moment for a theological production that is situated in history.
\end{abstract}

Keywords: Coronavirus. Johann Baptist Metz. Christian praxis.

\title{
Introdução
}

É comum, diante de uma situação adversa, que o ser humano se pergunte sobre o porquê de tal acontecimento. Diante de uma situação, mesmo que às apalpadelas, como alguém que busca encontrar o interruptor de luz em um quarto escuro na esperança de encontrar a luz, buscamos algum horizonte, alguma perspectiva. O ano 2020 foi atípico. Muito diferente de tudo o que a humanidade havia vivido. A sociedade busca, então, um horizonte ao qual possa se apegar. Talvez a vacina represente tal horizonte mesmo quando a política de vacinação não seja célere e tampouco eficaz.

Neste artigo não temos o objetivo de entender teologicamente a pandemia. Embora necessária, tal reflexão está para além de nosso intuito principal. Antes, assumimos como objetivo entender qual a relevância de uma produção teológica, sobretudo a de cunho pastoral ou práxico, que se debruça sobre esta realidade pandêmica, inclusive buscando entendê-la em perspectiva teológica. Para tanto, nossa metodologia, embasada na consulta bibliográfica, consiste em identificar alguns aspectos da pandemia, sobretudo no que gera 
impacto nas vivências eclesiais e sociais. A produção teológica neste contexto será articulada a partir da função histórica da Teologia, embasado na teoria de Joahnn Baptist Metz. A história se torna, por consequência o lugar teológico onde a reflexão é produzida e sobre a qual se ocupa o teólogo. Deste modo o que possibilita uma produção teológica que seja atual e relevante é a sua capacidade de interação com a realidade na qual está inserida.

Não podemos limitar a Teologia àquela que é produzida na academia. Podemos aqui elencar três modos de se fazer Teologia, que a princípio se distinguem apenas por um rigor conceitual e metodológico, mas não se opõem. Há a Teologia oficial, que habita os documentos oficiais da Igreja, os pronunciamentos e a produção intelectual dos Papas, a Teologia do Magistério. Há outro modo de fazer Teologia, que é cotidiana ou popular. Trata-se da Teologia que se produz com a sabedoria vivencial, quando o fiel busca, diante das adversidades ou do sofrimento, pensar no porquê daquilo que lhe aflige ou mesmo na presença de Deus. Por fim há uma Teologia acadêmica, com uma linguagem e um método que lhe são próprios. ${ }^{1}$ Neste artigo nos delimitaremos à Teologia acadêmica e, dentro dela, sobretudo à Teologia Fundamental e à Teologia Pastoral que se ocupam respectivamente de temas como a fé, a revelação e a práxis cristã.

Ao estabelecer um diálogo com o contexto histórico no qual está inserida, a Teologia constrói um movimento práxico de interação entre o pensamento cristão e a ação cristã na história. A realidade humana é assumida de forma a ser base e o lugar teológico diante da qual se constrói algo novo. Assim a Teologia se torna elemento constitutivo de possibilidades eclesiais e existenciais diante do cenário pós-pandêmico.

\section{Tempos de incerteza}

Em aproximadamente um ano, entre março de 2020 e março de 2021, o Brasil somou mais de 300 mil mortos pelo coronavírus. Em junho de 2021 são quase 500 mil vítimas, isso segundo os dados oficiais. No início era comum o entendimento de que o vírus apresentava maior mortalidade ao contaminar

\footnotetext{
${ }^{1}$ É possível limitar a Teologia ao ambiente acadêmico? Se formos sensatos, é provável que não. Há uma relação entre a produção teológica, entendida como o discurso ou raciocínio que embasa a vivência eclesial e a comunidade cristã. Assim não é apenas o povo que precisa da Teologia para a sua instrução. A Teologia alimenta-se da vivência eclesial (ver METZ, J. B., A fé em história e sociedade, p. 173-174).
} 
pessoas acometidas por comorbidades, mas o vírus se mostrou mortal e agressivo inclusive com pessoas de fora dos chamados grupos de risco, o que levantou várias incertezas em relação ao futuro da pandemia.

Além das mortes, famílias enfrentaram o problema do desemprego e da precariedade do trabalho. Para os pequenos e médios comerciantes a pandemia pode ter sido um período cruel devido ao fechamento do comércio. Os grandes conglomerados, com serviços pela internet e uma estrutura estabelecida, foram capazes de se adaptar com mais rapidez e provavelmente lucraram com isso.

Durante os tempos mais duros da pandemia vividos em 2020/2021, quando as UTIs estavam cheias e o número de mortes diárias era exorbitante, foi comum escutarmos que a pandemia era democrática e assolava a todos de maneira muito parecida. $\mathrm{O}$ entendimento da pandemia como algo que aflige a todos pode até ser real se considerarmos a vulnerabilidade diante da morte, mas os mais pobres acabam por sofrer mais com a pandemia, seja pela falta de acesso à saúde, seja pela falta de condições de se organizar financeiramente.

Em geral a pandemia exponenciou problemas que já existiam na sociedade como a desigualdade social, o endividamento da população e a volta da fome ao cenário social. ${ }^{2}$ Para a maioria da população brasileira que não conta com reserva financeira e que perdeu a renda, resta a assistência vinda do poder público. ${ }^{3}$

O período pós-pandemia - pelo menos se considerarmos a nossa esperança de um processo de vacinação que seja eficaz - provavelmente será um tempo de muito sofrimento, seja no âmbito humano e familiar, seja no âmbito das dinâmicas sociais. ${ }^{4}$ Mas é certo que serão tempos de incerteza e de reconstrução. A religião - e com ela a Teologia - tem uma dupla função: a primeira diz respeito ao entendimento da realidade de sofrimento e da assistência religiosa. Por que famílias que buscaram se resguardar perderam vários de seus membros e outras não foram assoladas pela contaminação e pela morte? A outra função é a da construção de um futuro que tenha sentido, mesmo em meio à tragédia.

É comum que entendamos a morte como um mal, sobretudo quando ela se concretiza em contextos trágicos, como é o caso das mortes causadas pela

\footnotetext{
${ }^{2}$ DOWBOR, L., Além da pandemia, p. 30-31.

${ }^{3}$ DOWBOR, L., Além da pandemia, p. 40.

${ }^{4} \mathrm{O}$ economista brasileiro Ladislau Dowbor entende a pandemia na confluência de algumas crises que já estavam em decurso: a crise ambiental, a crise da desigualdade, o caos financeiro e a própria pandemia (DOWBOR, L., Além da pandemia, p. 25).
} 
COVID-19. Outras catástrofes já na modernidade se constituíram verdadeiros episódios de teodiceia. Seja o terremoto de Lisboa em 1755, ou mortos em Auschwitz na Segunda Guerra Mundial fizeram a humanidade se questionar sobre a origem do mal e sobre a aparente ausência de Deus. Mas não seria essa a questão central do coronavírus. ${ }^{5}$

O coronavírus e sua pandemia tem relação com a ação humana, com seus hábitos e com suas características biológicas. Não se trata de uma catástrofe de ordem natural como o terremoto. Tampouco se trata de um genocídio causado por posições políticas como é o caso de Auschwitz. Embora os campos de concentração possam nos ajudar a entender a relação da humanidade com o mal, as circunstâncias são diferentes.

Muito se compara a pandemia do coronavírus à gripe espanhola. A questão que emerge do cenário pandêmico não é necessariamente de onde vem o mal ou por que Deus haveria permitido que isso acontecesse, mas como nós, seres humanos, nos organizaremos? Quais os horizontes que ainda são passíveis de serem guias da humanidade? Que humanidade queremos? ${ }^{6}$

A morte, por mais dolorida que seja, não é necessariamente um mal. Quando olhamos para a irmã morte da cosmovisão franciscana ou a morte de Jesus na cruz como entrega de amor, ou ainda para as práticas funerárias das religiões mais antigas, percebemos que o fim da vida é rezado, explicado e celebrado. O problema da morte no contexto da pandemia está no modo como se morre. É a morte solitária daqueles que, entubados, não contam com a presença da família, a morte sofrida daqueles que passam pelos hospitais de campanha, a morte do familiar que não tem direito a um funeral por questões sanitárias.

O coronavírus colocou o ser humano em uma situação de vulnerabilidade e a relação com a morte recebeu contornos que não se viu em uma geração que não necessariamente viveu a gripe espanhola ou mesmo os impactos da Segunda Guerra Mundial.

Os primeiros meses de 2021 trouxeram um novo cenário à pandemia no Brasil. As UTIs lotadas fizeram com que pessoas morressem à espera de uma vaga. Os profissionais da saúde foram colocados diante de um dilema: escolher quem deve ou não ser atendido e, por consequência, quem tem maior possibilidade de morrer ou ficar vivo. A capacidade de ditar quem deve viver

\footnotetext{
${ }^{5}$ KASPER, W., El coronavirus como interrupción, p. 18.

${ }^{6}$ KASPER, W., El coronavirus como interrupción, p. 19.
} 
ou morrer, entendida por Mbembe como o princípio do poder da necropolítica, ${ }^{7}$ no contexto de pandemia se tornou uma tragédia.

Toda a relação da morte no contexto da pandemia se torna ainda mais complexa para o ser humano pois, diferente dos outros animais, o ser humano vive a morte com sentido. A morte não é apenas uma passagem biológica. A ela é atribuído um sentido ou até mesmo a expressão do poder. ${ }^{8} \mathrm{O}$ modo como se morre demonstra quem somos, as relações que temos e as crenças que carregamos e de certa forma a pandemia comprometeu essa lógica.

Os tempos incertos levaram a sociedade a repensar várias de suas concepções. A religião como um elemento constitutivo da nossa sociedade também tem sua contribuição na articulação das narrativas que buscam entender a pandemia, mas também no apontamento de horizontes para o póspandemia.

\section{Uma Teologia histórica em meio à tragédia}

O cristianismo é a religião da ressurreição, é a religião do reino de Deus anunciado historicamente por Jesus de Nazaré. A dimensão escatológica do cristianismo tem incidências diretas e reais no contexto histórico onde se é vivido o evangelho de Jesus não limitando-se a ser um conjunto de expectativas para o pós-morte. Mas como anunciar a ressurreição àqueles que nem ao menos puderam velar seus mortos? ${ }^{9}$

Diferentes contextos históricos impelem a Teologia cristã a se repensar. A produção teológica costuma, sabiamente, olhar para o passado para enxergar momentos análogos capazes de mostrar caminhos e horizontes. O teólogo alemão Metz entende Auschwitz como um momento paradigmático para a produção teológica, sobretudo no que diz respeito a uma relação da Teologia com a história. Mesmo sendo um problema diretamente relacionado aos judeus, a catástrofe de Auschwitz haveria de despertar a empatia dos cristãos e, consequentemente, um diálogo com aquela realidade..$^{10}$ Diante de situações trágicas, não é aceitável o silêncio da sociedade, dos cristãos e porque não dizer, da Teologia:

\footnotetext{
${ }^{7}$ MBEMBE, A., Necropolítica, p. 5-6.

${ }^{8}$ HAN, B.-C., Morte e alteridade, p. 15.

${ }^{9}$ MENDOZA-ÁLVAREZ, C., A ressurreição como antecipação messiânica, p. 38.

${ }^{10}$ METZ, J. B., Para além de uma religião burguesa, p. 26.
} 
Só podemos confiar na História e extrair normas para nosso comportamento se não negarmos suas derrotas e não embelezarmos suas catástrofes. Ter uma consciência histórica e procurar viver desta consciência significa precisamente não fugir à realidade das catástrofes; significa também jamais negar ou ridicularizar, em qualquer modo que seja, uma única autoridade: a autoridade dos sofredores. ${ }^{11}$

Metz assume ainda a metáfora do sentar-se à mesa como um sinal de comensalidade dos cristãos não somente entre si, mas na relação com a sociedade e com a história. Ao celebrar o pão eucarístico o cristianismo é impelido a alargar sua mesa para o mundo que o cerca, vivendo a caridade que é celebrada. ${ }^{12}$ A mesa e a partilha do pão acontecem em perspectiva ecológica, ${ }^{13}$ integral, remetendo-se à vivência com o todo. O Papa Francisco aponta uma perspectiva parecida e mais ampla quando aponta para a vivência na Casa Comum. E o fato de habitarmos o mesmo ambiente e compartilharmos das mesmas aflições e problemas, nos impele à mobilização fraterna. ${ }^{14}$ Todas as questões pertinentes à vivência da Casa Comum acabam por serem também pertinentes aos cristãos e, por consequência, à Teologia.

A produção teológica não pode abdicar da história. Apartar-se das circunstâncias históricas pode ter como consequência o equívoco de fazer concessões a si mesma, ${ }^{15}$ entendendo-se como mais importante que a história da salvação. Assim a Teologia se faz presente no interior da história, possibilitando um melhor entendimento dela, tornando-se, assim como a Igreja, sinal historicamente palpável e ativo, superando a dualidade "Igreja-mundo" e entendendo que também a Teologia, como produção eclesial, está no mundo. ${ }^{16}$

Entender a Teologia como um estudo historicamente situado pode levar à questão de Deus como o objeto estudado pela Teologia. Mas poderia Deus ser entendido como o objeto da Teologia? Esta é uma pergunta complexa e sem uma resposta categórica. Mas o entendimento da Teologia como um olhar historicamente circunstanciado aponta para a concepção de Deus vivencial e não objetificável, onde Deus é horizonte de nossa experiência. ${ }^{17}$

\footnotetext{
${ }^{11}$ METZ, J. B., Para além de uma religião burguesa, p. 27.

${ }^{12}$ METZ, J. B., Para além de uma religião burguesa, p. 54.

${ }^{13}$ METZ, J. B., Para além de uma religião burguesa, p. 47.

${ }^{14}$ LS 164.

${ }^{15}$ METZ, J. B., Teologia do mundo, p. 12.

${ }^{16}$ METZ, J. B., Teologia do mundo, p. 17.

${ }^{17}$ HAUGHT, J. F., O que é Deus?, p. 35.
} 
O cristianismo entende que Deus atua historicamente. Sendo relação com a história, é o Deus que se nos apresenta, que conosco se relaciona, assumindo cores e rostos coerentes com as circunstâncias histórias. Ele é o Emanuel, não se limitando à sua dimensão supra histórica, mas sendo na história e participando dela. ${ }^{18}$ Ao se encarnar, Deus não renega o mundo, mas o aceita "irrevogavelmente no seu Filho". ${ }^{19}$ Sendo assim a Teologia é chamada a pensar não a profanização do mundo, mas sua cristificação, ou seja, não se trata de negar o mundo, mas de plenificá-lo. ${ }^{20}$

O mundo é contraditório. A história da salvação não é linear. Ela é dialógica, processual e acompanha as circunstâncias culturais e históricas. Por consequência, a fé humana é sempre histórica pois é na história que o ser humano vive. ${ }^{21}$ Essa concepção de Metz traz uma mudança de paradigma: da divinização do mundo para a o mundo hominizado, ${ }^{22}$ entendido aqui como o mundo "do homem", próprio do ser humano. ${ }^{23} \mathrm{O}$ mundo divinizado - ou numinizado ${ }^{24}$ - significa a negação da natureza humana, o que seria uma contradição perante a Encarnação. Deus não nega a criação, mas a quer plenificada. Essa plenificação, contudo, só se torna possível com a compreensão do mundo hominizado como parte da criação.

O mundo hominizado é espaço para a experiência de fé e de salvação à medida que o cristão estabelece uma aceitação de sua realidade humana que não significa a aceitação da uma realidade nociva e hostil ao ser humano, mas à aceitação de sua própria circunstância histórica. ${ }^{25}$

${ }^{18}$ METZ, J. B., Teologia do mundo, p. 18-19.

${ }^{19}$ METZ, J. B., Teologia do mundo, p. 18.

${ }^{20}$ METZ, J. B., Teologia do mundo, p. 46.

${ }^{21}$ METZ, J. B., Teologia do mundo, p. 55-56.

${ }^{22}$ Hominização aqui não deve ser confundido com o termo utilizado pela antropologia que diz respeito à evolução dos primatas. Metz se refere às características próprias do universo humano. Hominização, então, diz respeito ao antropo e não ao andrógeno. Optamos por não lançarmos mão de neologismos pois o objetivo do artigo não é discutir o conceito, mas estabelecer um diálogo entre ele e a situação de pandemia. Poderíamos, então, substituir hominizado por humanizado, mas este se refere às características humanas positivas e morais e não apenas aos aspectos próprios da condição histórica da humanidade. Por isso optamos por manter o hominizado, recorrendo a esta nota para necessários esclarecimentos.

${ }^{23}$ METZ, J. B., Teologia do mundo, p. 59.

${ }^{24}$ A compreensão numinosa de Deus também é criticada por pensadores que entendem que Deus só pode ser abordado como sujeito e não como objeto, pensamento esse denominado também como Teologia negativa, ou seja, podemos dizer o que Deus não é, mas não o que Deus é. Mas seria possível afirmar algo objetivo sobre Deus? Essa Teologia positiva seria possível apenas por meio de analogias (ver HAUGHT, J. F., O que é Deus?, p. 7-8).

${ }^{25}$ METZ, J. B., Teologia do mundo, p. 69. 
A experiência do hominizado assume quatro características. 1. O mundo hominizado é pluralista, aqui no sentido de que cada ser humano é uma consciência única e constituem, na relação, uma realidade plural. ${ }^{26}$ Uma compreensão unificadora da consciência resultaria na falta de historicidade. 2. O mundo hominizado surge como um mundo que vai ser. Trata-se de um mundo de possibilidades que são construídas historicamente, de um mundo que vai sendo, de um mundo que é construído. ${ }^{27} 3$. O mundo hominizado é isento de milagres. Pode esta afirmação parecer insensível ou descrente da ação de Deus na história, mas a relação com Deus não pode se pautar unicamente pela experiência do milagre de forma imediatista. ${ }^{28} 4$. O mundo hominizado surge como um mundo desumanizado. A hominização do mundo não necessariamente corresponde à sua humanização, visto que o ser humano, como um ser de liberdade ou mesmo como um ser sujeito à circunstâncias históricas específicas. ${ }^{29}$

O ser da Igreja está diretamente relacionado à sua relação com o mundo, ou seja, com o modo como o cristianismo se relaciona com as circunstâncias históricas. E por consequência torna-se indispensável identificar a função eclesial da Teologia. Assim seja o discurso teológico, seja o discurso religioso, não podem limitar-se a aspectos endógenos, ocorrendo em um narcisismo eclesiológico. ${ }^{30}$ Sempre alocada em uma circunstância histórica, tanto à Igreja como à Teologia é imposta a responsabilidade da fé face à situação histórica do mundo. ${ }^{31}$

A Teologia estaria, para o teólogo Adolphe Gesché, a serviço da fé e, consequentemente, a serviço do ser humano, se debruçando sobre os desafios de seu tempo, escutando a história humana, buscando a compreensão e o discernimento acerta dos acontecimentos que fazem parte de seu tempo. ${ }^{32} \mathrm{E}$ é no diálogo com as circunstâncias históricas que a Teologia se torna capaz de contribuir para a produção de respostas e, mais ainda, na construção de um sentido para a existência. ${ }^{33}$

\footnotetext{
${ }^{26}$ METZ, J. B., Teologia do mundo, p. 70.

${ }^{27}$ METZ, J. B., Teologia do mundo, p. 71.

${ }^{28}$ METZ, J. B., Teologia do mundo, p. 73.

${ }^{29}$ METZ, J. B., Teologia do mundo, p. 73-74.

${ }^{30}$ METZ, J. B., Teologia do mundo, p. 79.

${ }^{31}$ METZ, J. B., Teologia do mundo, p. 80.

32 GESCHÉ, A., La teología, p. 30.

${ }^{33}$ GESCHÉ, A., La teología, p. 63.
} 


\section{O contexto da pandemia como lugar teológico}

O conceito lugar teológico tem sua origem na Teologia medieval e moderna. Um dos autores que melhor articularam o conceito foi o dominicano Melchor Cano. Em sua principal obra, De locis theologicis, publicada em 1563, o autor trata do como fazer Teologia. Cano defende a Teologia como uma reflexão sobre Deus que se dá a conhecer pela revelação. Os "lugares" analisados pela Teologia são as diferentes áreas ou espaços em que os argumentos podem ser encontrados e assim servir de base de desenvolvimento racional as verdades reveladas.

Tomando como base os Tópicos de Aristóteles que servem de base analítica em lugares comuns de onde você pode extrair toda a argumentação para qualquer caso de disputa, Cano traz proponentes de locais pela Teologia, a saber: (1) Autoridade da Escritura Sagrada; (2) autoridade das tradições de Cristo e dos apóstolos; (3) autoridade da Igreja Católica; (4) autoridade dos concílios; (5) autoridade da Igreja Romana; (6) autoridade dos santos padres; (7) autoridade dos teólogos escolares; (8) a razão natural; (9) a autoridade de filósofos; e (10) autoridade da história humana. ${ }^{34}$

O clássico de Clodovis Boff sobre o método teológico distingue o objeto teológico em seu aspecto formal e material. Enquanto o material diz respeito ao que se estuda, o formal diz respeito ao como se estuda e este último - o objeto formal - indica o aspecto sobre o qual se analisa o objeto escolhido. ${ }^{35}$

A realidade se apresenta como um lugar teológico não somete por ser um tema estudado pela Teologia, mas também por ser, o entendimento da realidade o entendimento do próprio Deus que se nos manifesta. A volta à experiência do cotidiano tem se mostrado um caminho fértil à produção teológica. A vivência do singular permite uma relação real com a condição humana, sempre singular. ${ }^{36}$

Haveria algum limite ou proibição à Teologia? Existe algum tema que lhe seria proibido? À priori, não. Isso porque a Teologia pode se ocupar de uma variedade infinita de objetos pois o que a caracteriza é o seu método. Gesché cita que a única proibição à Teologia e ao teólogo é a misantropia, ${ }^{37}$ ou seja, o ódio à humanidade. Teria, então, a Teologia o direito de não abordar

\footnotetext{
${ }^{34}$ CANO, M., De locis Theologicis, p. 8-10.

${ }^{35}$ BOFF, C., Teoria do método teológico, p. 41.

${ }^{36}$ DUQUOC, C., A teologia no exílio, p. 77.

${ }^{37}$ GESCHÉ, A., La teología, p. 25.
} 
a pandemia? Seria essa uma postura coerente àqueles que buscam explicações e narrativas históricas para a vivência da fé? É sensato e responsável dizer que não. A Teologia, bem como a Igreja, como busca de conhecimento e vivência da fé de forma histórica e circunstanciada, deve buscar discernir acerca do momento atual. Aquilo que aflige a humanidade deve também afligir os seguidores de Jesus.

\section{Implicações teológico-pastorais em tempos de pandemia e pós-pandemia}

O pós-pandemia ainda é uma incógnita. Pouco sabemos sobre o final da pandemia, sobre o término da espera pela vacina ou sobre o modo como o mercado se comportará. Mas parece certo que a pandemia faz com que a sociedade, no mínimo, chegue a algumas constatações. Não chegamos ao fim da história e o mundo moderno está longe de ser seguro e estável. ${ }^{38} \mathrm{E}$ independente de implicar em uma mudança de horizonte ou de atitude, a pandemia causará, no mínimo, uma revisão de princípios e hábitos. ${ }^{39}$

Igreja e Teologia têm a função de serem sinal de esperança para o mundo construindo possibilidades. ${ }^{40}$ Dialogando com a existência humana, Igreja e Teologia devem viabilizar vivências de redenção e emancipação que aludem e emanam da redenção libertadora em Jesus e por meio dele. ${ }^{41}$ Mas para que tenha condição de propor possibilidades para o pós-pandemia, a Teologia necessita ocupar-se do entendimento deste momento histórico.

\subsection{Mais individualizados}

É comum a afirmação de que vivemos em um mundo globalizado, seja por assimilarmos uma cultura com características mundializadas, marcada pelo ideal liberal, pela universalização da cultura mercantil e pela tecnociência do consumo ${ }^{42}$ seja pela abrangência do controle econômico de uma globalização marcada pela perversidade dos processos que anulam as

\footnotetext{
${ }^{38}$ PASSOS, J. D., Do micro ao macro, p. 99-100.

${ }^{39}$ PASSOS, J. D., Do micro ao macro, p. 104.

${ }^{40}$ METZ, J. B., Teologia do mundo, p. 81.

${ }^{41}$ METZ, J. B., A fé em história e sociedade, p. 144.

${ }^{42}$ LIPOVETSKY, G.; SEROY, J., A cultura-mundo, p. 8-9.
} 
iniciativas de organização local. ${ }^{43}$ Ironicamente - pois não esperamos que um vírus seja sujeito responsável pelos processos globais -, talvez a pandemia seja uma das poucas experiências realmente globais, ${ }^{44}$ e isso pela capacidade de capilarização e contágio do vírus.

Paradoxalmente, uma experiência mundializadas fez com que parte da população buscasse se resguardar. As comunidades eclesiais celebraram as Semanas Santas de 2020 e 2021 transmitindo os ritos pelas redes sociais. As missas e cultos, as atividades comunitárias e pastorais, os encontros catequéticos, as novenas em família e grupos de ruas deixaram de se reunir. Tal processo exponenciou as características modernas de religiosidade onde a satisfação do indivíduo se torna critério de adesão religiosa. As comunidades cristãs, por sua vez, interromperam processos catequéticos, trabalhos pastorais - pelo menos no modelo convencional - e atendimento ao público nos momentos mais críticos da pandemia. As atividades coletivas que pediam a presença física dos fiéis sofreram impactos

Não saberemos quão grande será o impacto desta individualização na vivência eclesial. Mas o momento pós-pandemia pede maior atenção à comunidade cristã como meio de diálogo com a realidade local. É por meio dos relacionamentos e vínculos comunitários que possibilitamos um diálogo entre a vivência cristã e as histórias pessoais. A comunidade cristã tem um importante papel na construção da vivência cristã e abdicar das relações comunitárias pode gerar uma religiosidade individualizada e, por consequência, desconectada dos processos coletivos. Outro risco do pós-pandemia é que a manutenção institucional das comunidades desgastadas economicamente e pastoralmente por consequência da pandemia se sobreponha às vivências eclesiais.

\subsection{Mais vulneráveis às questões sociais e econômicas}

De certa forma é muito difícil encontrarmos alguém que não tenha sido afetado pela pandemia, seja em maior ou menor intensidade. Não diremos aqui que todos fomos afetados de alguma forma por uma preciosidade acadêmica. Há aqueles que perderam seus parentes, há quem foi demitido do emprego e há quem demitiu, há quem ficou em casa, resguardando-se e há quem não teve o direito de se resguardar para assegurar o seu sustento.

\footnotetext{
${ }^{43}$ SANTOS, M., Por uma outra globalização, p. 19.

${ }^{44}$ HALÍK, T., La pandemia como experiencia ecuménica, p. 79.
} 
Há quem saiu de casa por prestar algum serviço de necessidade básica e há quem de alguma maneira teve sua vida prejudicada pela ausência ou deficiência de algum serviço básico.

As cidades que mais sofreram as consequências da pandemia - considerando sobretudo mortes e infectados - são as grandes cidades, as metrópoles e megalópoles, que se constituem verdadeiros aglomerados industriais.

O modelo da sociedade urbana e moderna, da sociedade industrial com origens burguesas, é o da relação de domínio da natureza. A lógica predatória, consequência de uma leitura equivocada do versículo bíblico "sede fecundos e multiplicai-vos, enchei a terra e submetei-a" $(\mathrm{Gn} 1,28)$ leva ao entendimento técnico-instrumental do meio ambiente..$^{45}$

A pandemia também revelou a face mais cruel do capitalismo global. Somos reféns da sociedade global mas percebemos o quanto as estruturas sociais e econômicas são frágeis e o quanto somos incapazes - pelo menos até certo ponto - de cuidarmos das pessoas. Contudo muitas iniciativas locais se levantara, nas últimas décadas, como vozes de resistência frente ao sistema global. ${ }^{46}$

A pandemia mostrou-se ser um tempo oportuno para se repensar o mundo, sua lógica global, sua lógica econômica capitalista. Não há lado bom da pandemia. É nociva a ideia de que podemos tirar um lado bom da morte de milhares de pessoas, do sofrimento de seus familiares e do sofrimento daqueles que sofrem nos hospitais ou sofrem com as consequências econômicas da pandemia. Mas podemos entender que a pandemia é um momento oportuno para repensarmos os modelos sociais que vivemos e que queremos viver. Neste sentido a Teologia tem a função de se ocupar do espaço público, como a Teologia que trata do público, ${ }^{47}$ do comum, da Casa Comum.

A sociedade de consumo foi sucedida pela cultura de consumo. ${ }^{48}$ Isso significa que a lógica do consumo se torna cultural, embasando as relações e comportamentos e mesmo as relações que não são comerciais assumem suas características.

\footnotetext{
${ }^{45}$ KASPER, W., El coronavirus como interrupción, p. 23.

${ }^{46}$ HALÍK, T., La pandemia como experiencia ecuménica, p. 80.

${ }^{47}$ HALÍK, T., La pandemia como experiencia ecuménica, p. 81.

${ }^{48}$ PASSOS, J. D., Do micro ao macro, p. 108.
} 


\subsection{Mais eclesiais?}

A vivência cristã é caracterizada pela perspectiva pascal. O Deus vivo e o túmulo vazio (Mc 16,1-8) são perspectivas pascais que motivam a práxis cristã. ${ }^{49}$ Assim o cristão é sempre comunicador da ressurreição e da vida, tornando-se testemunha do Evangelho. Esta é também a tônica do Vaticano II, das assembleias do CELAM que aconteceram em Medellín até Aparecida, dos processos catequéticos atuais que tratam da inspiração catecumenal, do entendimento do laicato como sujeito eclesial.

A pandemia de alguma forma enfatizou que a religiosidade de massa, por si só, não sustenta a vivência eclesial. E essa mesma lógica que de alguma forma não se contenta com o proselitismo dos templos repletos foi prejudicada pelo contexto da pandemia. Mas também não podemos recorrer à pregação apocalíptica da falência das comunidades cristãs. $\mathrm{O}$ cristianismo é comunitário e não se sustenta sem seu aspecto eclesial. Trata-se então de entender o cristianismo como uma proposta de vida que abarca a vida eclesial e sacramental e a espiritualidade cotidiana que faz de cada cristão um buscador, ou seja, um vocacionado que constrói uma vida com sentido. ${ }^{50}$

Ao mesmo tempo o contexto da pandemia nos inclina à percepção e à vivência do Deus de Jesus que é o Deus que sofre. O amor de Jesus revelou um amor pessoal. ${ }^{51}$ Por consequência, a imagem do Deus de Jesus é mais empática que triunfante. Se há um triunfo, é o do amor concreto, vivencial, que se faz presente sobretudo nas situações de aparente desolação como na cruz e no túmulo vazio. A pandemia não somente pede uma revisão dos modelos sociais, mas também dos modelos eclesiais que vivemos e não é possível nenhuma revisão de modelos eclesiais sem uma fundamentação teológica.

\footnotetext{
${ }^{49}$ KASPER, W., El coronavirus como interrupción, p. 32.

${ }^{50}$ Halík entende o cristianismo como uma possibilidade de conversão pessoal que passa por aspectos superficiais do cotidiano, mas também pelos aspectos mais profundos da existência. A conversão entendida como metanoia assume, nos tempos atuais, parâmetros psicológicos, sociais e religiosos que constroem o ser humano em todas as suas relações. Tal processo é concomitante à descoberta da mística cristã (HALÍK, T., La pandemia como experiencia ecuménica, p. 93-94).

${ }^{51}$ FORTE, B., La fe en el Dios de Jesucristo y la pandemia, p. 40.
} 


\section{Conclusão: entre incertezas e possibilidades}

A pandemia não permite previsões ingênuas. Mas nos permite - e na verdade exige de nós - uma revisão dos modelos sociais vividos. A pandemia revelou a importância dos poderes e das estruturas públicas. No Brasil, se não fosse a estrutura do SUS (Sistema único de Saúde), a tragédia seria ainda maior. E mesmo as várias formas de auxílio governamental não impediram que as pessoas não caíssem na miséria. A fome voltou a fazer parte da rotina de muitos brasileiros e grupos religiosos, paróquias e igrejas evangélicas desenvolveram sua função social ocupando-se em cuidar desta parte da população.

Mas a pandemia também permite a revisão da própria Teologia que não pode, nem deve ser vista como uma área monolítica, onde todos os teólogos e suas áreas de pesquisa tratam do mesmo assunto. Contudo, como área de conhecimento ela tem uma função tanto social quanto eclesial e no exercício de sua função é necessário que tratem das condições históricas da sociedade na qual a própria Teologia está inserida. Tratar da pandemia é uma tarefa necessária sobretudo à Teologia Fundamental e à Teologia Pastoral.

Para a Teologia resta a função de pensar este momento da pandemia como lugar teológico, além de pensar o lugar do cristianismo na história e o cristão como sujeito histórico. Áreas de produção teológica como a Teologia Pública e disciplinas como a moral social são espaços privilegiados para pensar o contexto que vivemos. Mas também a Teologia Fundamental é desafiada a pensar a revelação em um contexto adverso. Quanto à realidade eclesial católica o desafio será grande. Após tempo de ausência, como será a participação litúrgica? Os processos catequéticos, que em muitas comunidades foram interrompidos por meses, por um ano ou até mais, conseguirão retomar seu caminho? A pastoral cristã católica migrará para a internet?

Por outro lado, o pós-pandemia se revela um momento histórico de possibilidade da volta a um cristianismo de vivências pessoais, com um menor apelo de massa e pequenas comunidades de vivências afetivas e efetivas. Os processos catequéticos podem se preocupar menos com uma catequização formal e cultural e se ocupar de processos iniciais mistagógicos. E a Teologia pode abrir-se ao diálogo com as realidades históricas e locais, possibilitando a constituição de uma práxis cristã. 


\section{Referências bibliográficas}

BÍBLIA de Jerusalém. São Paulo: Paulus, 2006.

BOFF, C. Teoria do método teológico. Petrópolis: Vozes, 2019.

CANO, M. De locis theologics. Madri: BAC, 2006.

DOWBOR, L. Além da pandemia: uma convergência de crises. In: PASSOS, J. D. (Org.). A pandemia do coronavírus. São Paulo: Paulinas, 2020. p. 2547.

DUQUOC, C. A teologia no exílio: O desafio da sobrevivência da teologia na cultura contemporânea. Petrópolis: Vozes, 2006.

FORTE, B. La fe en el Dios de Jesucristo y la pandemia. In: KASPER, W.; AUGUSTIN, G. (Eds.). Dios en la pandemia. Maliaño: Editorial Sal Terrae, 2020. p. 35-50.

FRANCISCO, PP. Carta Encíclica Laudato si’. São Paulo: Paulinas, 2015.

GESCHÉ, A. La teología. Salamanca: Ediciones Sígueme, 2017.

HALÍK, T. La pandemia como experiencia ecuménica. In: KASPER, W.; AUGUSTIN, G. (Eds.). Dios en la pandemia. Maliaño: Editorial Sal Terrae, 2020. p. 79-102.

HAN, B.-C. Morte e alteridade. Petrópolis: Vozes, 2020.

HAUGHT, J. F. O que é Deus? Como pensar o divino. São Paulo: Paulinas, 2004.

KASPER, W. El coronavirus como interrupción. In: KASPER, W.; AUGUSTIN, G. (Eds.). Dios en la pandemia. Maliaño: Editorial Sal Terrae, 2020. p. 13-33.

LIPOVETSKY, G.; SEROY, J. A cultura-mundo: Resposta a uma sociedade desorientada. São Paulo: Companhia das Letras, 2011.

MBEMBE, A. Necropolítica: Biopoder, soberania, estado de exceção, política da morte. São Paulo: N-1 edições, 2020.

MENDOZA-ÁLVAREZ, C. A ressurreição como antecipação messiânica: luto, memória e esperança a partir dos sobreviventes. Petrópolis: Vozes, 2020. METZ, J. B. A fé em história e sociedade: Estudos para uma teologia fundamental prática. São Paulo: Paulinas, 1981. 
METZ, J. B. Para além de uma religião burguesa: sobre o futuro do cristianismo. São Paulo: Paulinas, 1984.

METZ, J. B. Teologia do mundo: da sociedade, da política, da paz. Rio de janeiro: Moraes Editores, 1969.

PASSOS, J. D. Do micro para o macro: estruturas em mutações a olho nu. In: PASSOS, J. D. (Org.). A pandemia do coronavírus. São Paulo: Paulinas, 2020. p. 95-111.

SANTOS, M. Por uma outra globalização: Do pensamento único à consciência universal. Rio de Janeiro: Record, 2013.

Welder Lancieri Marchini Doutor em Ciência da Religião pela Pontifícia Universidade

Católica de São Paulo Rio de Janeiro / RJ - Brasil E-mail: welder.marchini@gmail.com

Recebido em: 01/04/21

Aprovado em: 15/06/21 